\title{
Tertiary Students' Usage of Vocabulary Learning Strategies: A case study
}

\author{
Gurnam Kaur Sidhu¹, Nor Karina Mohamad Nor ${ }^{2}$ \\ ${ }^{1}$ Faculty of Education, SEGi University, Taman Sains Selangor, Petaling Jaya, Selangor, Malaysia \\ 2Faculty of Education, Universiti Teknologi MARA, Shah Alam, Selangor, Malaysia \\ gurnamgurdial@segi.edu.my, gurnamsidhu213@yahoo.com, karinamohd@yahoo.com \\ Tel of 1st Author: +60192375826
}

\begin{abstract}
Instructors often lament on students' limited critical reading skills due to "vocabulary deficit." Therefore, this study investigated the vocabulary size and vocabulary learning strategies of $120 \mathrm{ESL}$ respondents in a tertiary institution in Malaysia. Data were collected using a vocabulary test, a questionnaire, and semi-structured interviews. The findings revealed that the most favoured strategies were "determination strategies" which reflected respondents' usage of shallow thinking while least favoured were "cognitive strategies" that demanded higher-level mental processing. No significant difference was recorded in strategy use based on gender. No relationship was found between the respondents' vocabulary size and vocabulary learning strategies.
\end{abstract}

Keywords: tertiary students; vocabulary learning strategies; vocabulary size

eISSN: 2398-4287 @ 2020. The Authors. Published for AMER ABRA cE-Bs by e-International Publishing House, Ltd., UK. This is an open access article under the CC BYNC-ND license (http://creativecommons.org/licenses/by-nc-nd/4.0/). Peer-review under responsibility of AMER (Association of Malaysian Environment-Behaviour Researchers), ABRA (Association of Behavioural Researchers on Asians) and cE-Bs (Centre for Environment-Behaviour Studies), Faculty of Architecture, Planning \& Surveying, Universiti Teknologi MARA, Malaysia.

DOI: https://doi.org/10.21834/ebpj.v5iSI1.2318

1.0 Introduction

Without grammar, very little can be conveyed, Without vocabulary, nothing can be conveyed. (Wilkins, 1972, p.111)

The above quotation needs no elaboration as it speaks volumes about the importance of vocabulary both in language learning and conveying messages in our daily routines. There is no denying that words are the foundational blocks of language comprehension because vocabulary is "the glue that holds stories, ideas and content together" (Rupley, Logan \& Nicholas, 2006, p. 339). Any learning, be it a language or academic discipline, is meaningless without a good knowledge of vocabulary as it helps to convey meaning and is the bridge that connects one word to another in sentences or utterances (Wilkins, 1972). Hence, vocabulary is the foundation for growing language literacy as it allows one to use the language effectively and efficiently in daily life. It is also central to one's reading ability and academic achievement (Folse, 2004).

Though vocabulary is a critical component in language learning, instructors often lament on tertiary students' limited critical reading skills as a result of "vocabulary deficit." Hence, much criticism is often hurled that the study of vocabulary is ignored and overshadowed by other language skills and grammar (Meara, 2002). There is no denying that vocabulary size and use of vocabulary learning strategies are essential for students to help them cope with academic tasks at all levels, including tertiary education. Thus this paper explores the use of vocabulary learning strategies among tertiary students in an institution of higher learning in Malaysia.

eISSN: 2398-4287 ( 2020. The Authors. Published for AMER ABRA cE-Bs by e-International Publishing House, Ltd., UK. This is an open access article under the CC BYNC-ND license (http://creativecommons.org/licenses/by-nc-nd/4.0/). Peer-review under responsibility of AMER (Association of Malaysian Environment-Behaviour Researchers), ABRA (Association of Behavioural Researchers on Asians) and cE-Bs (Centre for Environment-Behaviour Studies), Faculty of Architecture, Planning \& Surveying, Universiti Teknologi MARA, Malaysia.

DOI: https://doi.org/10.21834/ebpj.v5iSI1.2318 


\subsection{Literature Review}

Learning any language is meaningless without having a good knowledge of the words or vocabulary of the target language as words convey meanings in a language and are a bridge the connects one word to another in sentences or utterances (Wilkins, 1972). Vocabulary is not only a word unit in a language but also a lexical unit with many interpretations on its definitions, forms, and uses depending on different contexts that it is being used (Nation, 2013). Thus, it is evident that vocabulary learning is a foundation for growing the language's literacy and allows one to use the language effectively and efficiently in daily life. More importantly, vocabulary learning involves continuous, non-stop processes which build and expand the number of words to sharpen the knowledge of different aspects of a word or some words such as the grammatical categories, pragmatics and sociolinguistic values (Belisle, 1997). This is also concurred by Morgan and Rinvolucri (2004) who refer to the learning of vocabulary as a 'branching process' which is influenced by the learner's present, past and future experiences, and this often expands throughout one's lifetime in parallel with the growing difficulties of dealing with new and unfamiliar words in second language learning. Correspondently, Schmitt (2007) further highlighted that vocabulary knowledge is a vital tool for mastering second language acquisition and enhancing communicative competence among ESL learners. Schmitt (2007) also reiterated that a sufficient number of words are crucial for enhancing the four skills of language learning affects one's education in school and future employment.

In the context of Malaysia where English is taught as a second language (ESL, hereafter), past studies have revealed a deficit in tertiary students' vocabulary (Kaur, 2008; Moktar et al., 2010; Chen, 2011). This "vocabulary deficit" has consequently resulted in tertiary students' inability to cope with academic tasks. Insufficient vocabulary can hinder learners from having an adequate overall comprehension of a text during the reading process, including recalling the meaning of learned vocabulary when reading content thus distorting their overall vocabulary acquisition during reading (Chen, 2011). Furthermore, a study conducted by Mokhtar et al. (2010) found that a majority of tertiary students did not have a sufficient vocabulary size resulting in comprehension difficulties during the reading process. Chall and Jacobs (2005) further added that a high level of vocabulary size among learners corresponds with high reading comprehension and academic success. This was also articulated by Sidhu et al. (2016), who found that even postgraduate supervisors lamented their supervisees' lack of critical reading, writing, and conceptual skills due to their limited vocabulary. These studies highlight the importance of vocabulary size to help tertiary students cope with academic tasks.

However, research has indicated that vocabulary size can be enhanced through vocabulary learning strategies (VLS, hereafter). Studies have also indicated that VLS can be adopted to help assist learners' vocabulary processing and growth of vocabulary at all levels (O'Malley and Chamot, 1990; Schmitt, 2007; Nation, 2013). VLS refers to particular steps or techniques employed by learners, consciously or unconsciously, whenever they need to study words, which leads to the employment of selective strategies to learn the words (Schmitt, 2007). Looking into vocabulary size, Nation (2007) categorised the words according to their frequency levels, namely high and low-frequency levels. High-frequency words refer to the words that often occur in both spoken and written texts, for instance, the word 'the'. Nation defines low-frequency words as the vocabularies that infrequently appear in the common use of the language, such as the words 'maunder' and 'bawdy'. Such distinctions are related to how L2 learners acquire or learn the vocabularies; L2 learners need to acquire high-frequency words before proceeding with their learning of low-frequency words. This facilitates their text comprehension as the high-frequency words lead to a high level of text coverage. Hulstijin and Laufer (2001) added that the incidental and intentional learning using VLS can assist the vocabulary learning process as VLS range from 'shallow' to 'deeper' strategies. Teachers can include them during instruction so that learners can accommodate their needs of learning new vocabulary using different 'base words' of the lexical items such as derivatives and word forms (for instance, multiple meanings).

Among numerous categories of VLS postulated by researchers, the common classification system used in various studies is the one introduced by Schmitt (2007) whose categories are divided into two major classes and comprise of the following strategies: determination strategies, social strategies, memory strategies, cognitive strategies, and metacognitive strategies. The first class involves the discovery aspect of learning, which consists of determination strategies and social strategies that are useful in the initial discovery of a word's meaning. The second class involves consolidation aspects comprised of memory strategies, cognitive strategies, and metacognitive strategies which are useful for remembering a word once it has been introduced. Schmitt (2007) asserts that the two classes echo the distinctive processes in working out a new word's meaning and usage, which benefit the learner's word consolidation and retention for future use. Determination strategies assist learners in determining the definition of a word without external help. Social strategies are used to identify the meaning of a word by interacting with and learning from others which includes asking teachers, classmates, and native speakers. Memory strategies involve learners recalling vocabulary through mental processing by relating new words with the learners' background knowledge. Cognitive strategies involve repetition, making lists of new words, and keeping a vocabulary notebook. Finally, metacognitive strategies reflect the learner's capability to take chances in learning vocabulary, such as learning new words through English-language media, as well as choosing suitable VLS for newly acquired words (Schmitt, 2007). Schmitt (2007) also purports that with learners taking an active role and responsibility in the vocabulary learning process also demands the learners to make a shift towards more self-directed learning. Hence teachers need to expose learners to a variety of processes and VLS so that they can learn how to organize knowledge and skills to help them apply VLS effectively. Studies have also indicated that VLS also contribute to autonomous learning (Wenden, 1991).

Though vocabulary size and VLS is a much-explored area in the field of language learning and education as a whole, the need to conduct context-based research to help better understand learners' needs continues to exist. Therefore, the two main objectives of the study were to investigate the vocabulary size and the VLS employed by ESL tertiary students in an institute of higher learning. It also examined if there was any significant difference in the vocabulary size of the respondents based on gender. Finally, the fourth objective was to investigate if there was a relationship between the employment of VLS and the vocabulary size of tertiary students. 


\subsection{Methodology}

This study employed a descriptive correlational research design to examine the relationship between students' vocabulary size and the use of VLS. The study involved one faculty from an institution of higher learning (IHL, hereafter) located in Shah Alam, Selangor, Malaysia, where the medium of instruction is English. The study involved a total of 120 first-year ESL tertiary students and data were collected via a three-pronged mixed-method approach involving the use of a vocabulary size test (VST), a questionnaire on VLS, and semi-structured interviews. The VST employed in this study was a shorter version of the VST adopted by Nation \& Beglar (2007), while the questionnaire administered to investigate the specific strategies was Schmitt's (1997) vocabulary learning strategies questionnaire (VLSQ). The VLSQ comprised 41 items that employed the use of a five-point Likert-scale (never, seldom, sometimes, often, and always). Semi-structured interviews were conducted with 12 students. The quantitative data from the VST and VLSQ was organized and analysed by using Statistical Package for Social Sciences (SPSS) while the qualitative obtained from the semi-structured interviews were transcribed and analysed based on themes. Keeping in line with ethics in research and to maintain the confidentiality of respondents, the 120 students were referred to as S1 to S120, while the 12 students interviewed were coded as SA1 to SA12. All the information obtained was kept in a password-encrypted laptop, which could only be accessed by the researchers.

\subsection{Results}

The demographic profile of the respondents revealed that out of the total 120 students, $55 \%$ of the respondents $(n=66)$ were males, while the rest of the respondents were 54 females (45\%). For the Malaysian Secondary Five SPM English Language Examination (equivalent to $\mathrm{O}$ levels), results indicated that the majority (55.8\%) obtained a credit B while another $35.8 \%$ received a distinction $\mathrm{A}$. The remaining ten respondents (8.3\%) obtained a passing grade of $\mathrm{C}$. The background data indicated that the students possessed an average academic achievement and were moderate users of the English Language.

The first research objective of this study was to explore the vocabulary size of tertiary students. The results revealed that the students obtained a mean score of 38.7 out of a total score of 70 . To estimate the total vocabulary size of the respondents, the mean vocabulary size score was calculated by multiplying by 200 . This is because every five items in the test (the total items were 14 multiplied by five items) are samples of 1000 word-family levels whereby each item represented the knowledge of 200 word-families. Thus, the total vocabulary size of the respondents was 7746 word-families. Nation (2013) posited the importance for non-native speakers of English to achieve 98 per cent text coverage, which is equivalent to 8000 to 9000 word-families. The second research objective was to investigate the kind of VLS that were most and least frequently employed by the 120 respondents. The results are displayed in Table 1 below.

Table 1: Descriptive Statistics on the VLS Categories ( $n=120)$

\begin{tabular}{lcc}
\hline VLS Category & Mean & SD \\
\hline Determination & 3.53 & .551 \\
Social & 3.20 & .730 \\
Memory & 3.21 & .581 \\
Cognitive & 3.19 & .681 \\
Metacognitive & 3.34 & .644 \\
\hline Total & 3.30 & .505
\end{tabular}

Scale: $1-2.4$ = low strategy use, $2.4-3.5$ = medium strategy use, $3.5-5=$ high strategy use

Based on the findings obtained, the most frequently used VLS by the students were determination strategies $(M=3.53, S D=.551)$, followed by metacognitive strategies $(M=3.34, S D=.644)$. Findings also revealed that memory strategies $(M=3.21, S D=.581)$, social strategies $(M=3.20, S D=.730)$, and cognitive strategies $(M=3.20, S D=.681)$ were the least frequently employed by the respondents. Further analysis into the employment of determination strategies revealed that out of the seven (7) sub-strategies respondents employed, the most favoured strategy of vocabulary learning was the use of an English-English dictionary ( $M=3.95, S D=.858)$, followed by guessing the meaning from the context $(M=3.92, S D=.836)$, and the use of a Malay-Malay dictionary $(M=3.82, S D=.935)$. This finding was also supported by the qualitative data gathered from the interview sessions:

"I can learn so many words from a dictionary." (Respondent A2)

"It is fun to search the meaning in a dictionary... so much information about a word." (Respondent A6)

"Dictionary helps me to learn a word when l'm reading a textbook." (Respondent A8)

The second most favoured VLS was metacognitive strategies, which recorded a mean score of 3.34, illustrating that the respondents were only medium users of this category. Among the five (5) sub-categories, the respondents most favoured using English-language media (song, movies and using the internet) $(M=3.88, S D=.174)$ to improve their vocabulary skills, followed by paying attention when someone was speaking in English $(M=3.88, S D=.174)$, and testing themselves with word-tests $(M=3.59, S D=.174)$. These findings were also well-articulated by the respondents during the interview sessions:

"I will search for the meaning of the word in Google... think this is a faster way to find the meaning..." (Respondent A5)

"I always search for the meaning on the internet...mostly when I am reading my textbook because I always find difficult words in there...I will Google when I am studying for a test or exam." (Respondent A7)

"I like to read the posts from my friends on Facebook because I can learn new words from the English video or articles that they posted."

(Respondent A10)

The third most favoured VLS were memory strategies $(M=3.21, S D=.581)$, and the mean score revealed that the respondents were only medium users of this category. Among all 17 sub-strategies in this category, the most favoured strategy employed was studying 
the spelling of a word ( $M=3.46, S D=0.82)$, followed by remembering the words in scales (always, often, sometimes, never) if it often used $(M=3.44, S D=.960)$, and using the new word in a sentence. In the interview session, Respondent $A 6$ had this to say:

"English words have unique spelling, unlike Malay words that are much easier to be spelt. Because of that, some English words are difficult for me to understand the meaning... However, when I study the spelling of the difficult words while I try to remember the meaning, I found that it is much easier to remember the words..."

The least favoured memory strategies to remember words were: drawing a picture $(M=2.47, S D=.152)$, followed by making a mental image $(M=3.05, S D=.183)$, and using a physical action $(M=3.07, S D=.119)$. The two least favoured strategies were cognitive and social. Social strategies which recorded a mean score of 3.2 illustrated that the respondents were only medium users of social strategies. Among the five (5) sub-strategies within this group of VLS, the students most frequently employed the strategy of seeking help from classmates/peers for the meaning of a word $(M=3.83, S D=.938)$, followed by asking the teacher for a definition $(M=3.24, S D=.935)$. Students were less likely to attempt to familiarize themselves with difficult words by studying the words with their classmates ( $M=3.03$, $S D=1.069)$, or by getting their teacher/lecturer to check their presumed definition $(M=3.03, S D=1.065)$. The respondents' refusal to practice their recently learned words and to learn more new words by talking with native speakers was evident as this category recorded the lowest score $(M=2.86, S D=1.095)$. This finding was again supported by the interview sessions. For example, Respondent $A 6$ highlighted that she "never talked to any foreigners to practice or to learn new words" nor did she have any friends from English-speaking countries. Respondent A12 further added that "my friends are better in English, so I always ask them for the meaning" while Respondent A1 stressed that "I always ask the teacher and she is very kind and good. She will always help us understand better."

Finally, the least favoured VLS were cognitive strategies which are viewed as a consolidation group of strategies comprised of demanding mental processes to enhance the retention of learned words (Schmitt, 1997). Respondents in this study were also found to be medium users of this category $(M=3.2)$, and the most favoured cognitive strategies were repeating words aloud $(M=3.48, S D=.907)$, followed by highlighting/taking notes ( $(M=3.39, S D=.981)$, and writing the words down many times $(M=3.37, S D=.981)$.

The third objective was to examine if there was any significant difference in the vocabulary size of the respondents based on gender. Results also indicated that on the whole, the female respondents performed better (mean score=39.12) than their male (mean score=38.26) counterparts. Nonetheless, inferential statistics employing an independent sample t-test conducted revealed there was no significant difference $(\mathrm{t}(120)=.679, \mathrm{p}$-value $=.499)$ between the mean scores of male and female students.

The final research objective was to investigate if there was a relationship between the employment of VLS by the tertiary students and their vocabulary size. The findings of this study revealed that there is no association between the tertiary students' VST scores and the VLS employed $(r=-.071, p$-value =.443). The findings also indicated that the direction of the relationship is negative. This implies that any high or low frequency of usage of the VLS by the undergraduates has no relation with the undergraduates' VST scores. In other words, it can be concluded that regardless of the high frequency of use of VLS, the respondents would obtain a low score in the VST, and vice versa.

\subsection{Discussion}

The investigation into the vocabulary size of students involved in this study showed that the students only managed to obtain a mean score of 38.7 out of a total score of 70 . Nation (2013) posited the importance for non-native speakers of English to achieve 98 per cent text coverage, which is equivalent to 8000 to 9000 word-families. The results in this study implied that the students' vocabulary size was below the required level and that they would most probably face difficulties comprehending written texts needed for their basic academic learning. Nevertheless, this score reveals that they were within the range of 6000 to 7000 word-families for spoken texts, which indicates that they were able to comprehend English spoken texts more than the written texts.

Findings also indicated that the most favoured strategies were the use of determination strategies. This finding is similar to a study conducted by Asgari (2011) that depicted determination strategies, especially using a dictionary and guessing from the context as the most employed strategies because they were familiar with both strategies and used them frequently when encountering new words. Schmitt (2007) noted that determination strategies used by learners usually indicate that they are engaging in a shallow level thinking process and could be avoiding using strategies that require higher-order thinking levels. This is a concerning yet typical perception of low-proficiency language learners who perceive the strategies as sufficient and adequate to learn new words. Cognitive strategies involve direct control of the learning process that is complementary to metacognitive strategies.

Results also showed that there was no significant difference between the use of vocabulary strategies based on gender. Likewise, no significant difference in the male and female scores' on vocabulary size test was also noted by Fernandez-Fontecha (2014). Nonetheless, the findings of this study are in contrast with the study by Scarcella \& Zimmerman (1998). They found that the academic lexicon test scores of the male university learners are significantly higher than their female counterparts. They concluded that this exhibited the better-developed academic vocabulary among the male students due to their efforts of using the academic words in interactions compared to the female students.

Finally, the findings in this study also noted that there is no association between the tertiary students' VST scores and the VLS employed. Similar results were also recorded by other researchers such as Kalajahi \& Pourshahian (2012), who found that there was no correlation between the most frequently employed psycholinguistic strategies category and the vocabulary size of the undergraduate students. The imbalance in using the strategies, such as an overemphasis on cognitive strategies together with low usage of other categories of VLS, can impair the use of the strategies in developing more vocabulary knowledge. 


\subsection{Conclusion}

The findings of this study imply that students lack the awareness to use VLS to enhance their vocabulary size. To ensure our learners leave $\mathrm{IHL}$ as autonomous lifelong learners, the teaching and learning of vocabulary cannot continue to be ignored and overshadowed by other skills. It is imperative to help students eliminate the word stress from their vocabulary by putting into place a systematic vocabulary learning strategy program for ESL/EFL classrooms. Last but not least, it is pertinent to note that these findings cannot be generalized on the total population of tertiary students in Malaysia due to the small sample size involving only 120 respondents from one institution of higher learning. Henceforth, further research needs to be conducted to ascertain the vocabulary level of tertiary students in Malaysia involving a larger sample size that includes both private and public universities. Nonetheless, it cannot be denied that the findings do shed some light on the issue of "vocabulary deficit" and how this could consequently affect students' academic success. Therefore, ESL instructors need to integrate vocabulary learning strategies to enhance tertiary students' vocabulary size so that they can interpret, express and communicate more effectively.

\section{References}

Baleghizadeh, S., \& Golbin, M. (2010). The effect of vocabulary size on reading comprehension of Iranian EFL learners. Linguistic and Literary Broad Research and Innovation, 1(2), 33-44.

Belisle, T. A. (1997). Developing vocabulary knowledge in the immersion classroom. The bridge: From research to practice. Retrieved from http://www.carla.umn.edu/immersion/acie/vol1/Nov2017.pdf.

Chall, J. S., \& Jacobs, V. A. (1983). Writing and reading in the elementary grades: Developmental trends among low-SES children. Language Arts, 60(5), 617-626.

Chen, K. Y. (2011). The impact of EFL students' vocabulary breadth of knowledge on literal reading comprehension. Asian EFL Journal,51, 30-40.

Folse, K. S. (2004). Myths about teaching and learning second language vocabulary: What recent research says. TESL Reporter, 37 (2), 1-13.

Hulstijn, J., \& Laufer, B. (2001). Some Empirical Evidence for the Involvement Load Hypothesis in Vocabulary Acquisition. Language Learning, 51, 539-558.

Kaur, N., Othman, N. H., \& Abdullah, M. K. K. (2008). Lexical competence among tertiary students: Teacher-Students' perspective. The English Teacher 30(7): 90-104.

Kalajahi, S. A. R., \& Pourshahian, B. (2012). Vocabulary learning strategies and vocabulary size of ELT students at EMU in Northern Cyprus. English Language Teaching, 5(4), 138-149.

Lee, S. W. (2007). Vocabulary learning strategies of Korean University students: Strategy use, vocabulary size, and gender. English Teaching, 62(1),149-169.

Meara, P. (2002). The rediscovery of vocabulary. Second Language Research, 18(4). 393-407.

Mohktar, A. R., Rafizah, M. R., Mohammad F. Y., Zaharee A., Mahani M., Mohd. Izwan, Abdul R. M. (2010). Vocabulary knowledge of adult ESL learners. English Language Teaching, 1(3), 71-87.

Morgan, J., \& Rinvolucri, M. (2004). Vocabulary (2nd Ed.). New York, NY: Oxford University Press

Nation, P. (2013). Learning vocabulary in another language. (2nd. Ed.) Cambridge: CUP.

Nation, P., \& Beglar, D. (2007) A vocabulary size test. The Language Teacher. 31(7), 9-13.

O' Malley, J. M., \& Chamot, A. U. (1990). Learning strategies in second language acquisition. Cambridge, England: Cambridge University Press.

Rupley, W. H., Logan, J. W., \& Nichols, W. D. (2006). Vocabulary instruction in a balanced reading program. The Reading Teacher, 52(4), 239-260.

Schmitt, N., \& McCarthy, M. (1997). Vocabulary: Description, acquisition and pedagogy. Cambridge: Cambridge University Press.

Schmitt, N. (2007). Vocabulary in language teaching. Cambridge: CUP.

Sidhu, G. K., Lim, P. C., \& Chan, Y. F. (2016). Assessing the critical reading skills of postgraduate students; Perspectives of supervisors and supervisees. In S. Tang, L. Logonnathan (eds). Assessment for Learning Within and Beyond the Classroom, Singapore: Springer Pub. 43-54.

Waldvogel, D. A. (2013). The Relationships between vocabulary learning strategies and vocabulary size among adult Spanish foreign language learners. Journal of Language Teaching and Research, 4(2), 209-219.

Wenden, A. (1991). Learner Strategies for Leaner Autonomy. Hempstead: Prentice Hall. Wilkins, D. A. (1972). Linguistics in language teaching. Edward Arnold: London. 